\title{
Correction to: Schema Extraction for Deep Web Query Interfaces Using Heuristics Rules
}

\section{Chichang Jou ${ }^{1}$ (D)}

Published online: 25 June 2019

(C) Springer Science+Business Media, LLC, part of Springer Nature 2019

\section{Correction to: Information Systems Frontiers (2019) 21:163-174} https://doi.org/10.1007/s10796-018-9863-6

The original copy of this article included incorrect data for "authors and affiliations". A corrected version of the "authors and affiliations" data is provided below. The author would like to thank the editorial office and colleagues of Springer Science+Business Media, LLC for the assistance in correcting the error:

Department of Information Management, Tamkang University, New Taipei City, Taiwan

Pulisher's Note Springer Nature remains neutral with regard to jurisdictional claims in published maps and institutional affiliations

The online version of the original article can be found at https://oi.org/ 10.1007/s10796-018-9863-6

\section{Chichang Jou}

cjou@mail.tku.edu.tw

1 Department of Information Management, Tamkang University, New Taipei City, Taiwan 